\title{
Human Responses to Extreme Stress
}

\author{
Dr James Thompson \\ Department of Psychiatry \\ University College London Medical School \\ 48 Riding House Street \\ London W1N 8AA \\ UK
}

Tel 01713809470

Fax 01713231459

\begin{abstract}
$\underline{\text { Abstract }}$
The topic of risk perception is discussed in relation to data obtained from Japanese students, who appear to have a highly vigilant approach to life's dangers and to welcome warnings, but at the same time have a somewhat fatalistic attitude to their own lives. After an overview of conceptual issues regarding stress and disasters including earthquakes, examples of human responses to massive stress are presented in the cases of an Underground railway fire, an aeroplane hijacking, a ferry boat sinking and a terrorist bomb explosion on a city street. Data are also presented on the coping strategies which people use to attempt to process traumatic events, and therapeutic outcomes from controlled treatment trials.
\end{abstract}

\section{Human Responses to Extreme Stress}

The topic of Safety Control and Risk Management leads naturally to profound questions about our view of life. Each individual person has their own preferences as to the levels of risk they are willing to accept. These personal preferences may be reflected in all aspects of their life, though individuals may be willing to tolerate risks in some areas of activity, and yet avoid all dangers in other enterprises. A person may decide that one job has better prospects of security than another, that one sporting activity may be too dangerous to contemplate, that a particular investment is risky but that the risk is worth taking because of the prospect of higher returns. Attitudes to risk and reward may even influence the choice of a spouse.

Although individual differ in their attitudes to risk, entire cultures also vary in the way they approach the hazards of life. Some religions appear to encourage the view that life is determined by the will of God, and that precautions are limited in their value. Other cultures are not satisfied with the explanation that an accident is due to Fate. They are far more interested in seeking causes, and as a consequence are often searching for someone to blame for every calamity. It is said that in the United States there is no longer any such thing as "an act of God", and that the legal system can always track down someone who is responsible for not preventing the disaster, or at least for not warning of it in time.

There are many approaches to the subject of risk (Dowie and Lefrere, 1980) and many conceptual schemes in which to classify human errors (Rasmussen et al. 1987, Reason 1989). 
One simplified conception of the relationship between risks and opportunity is to display the different positions of different attitudes in risk-opportunity space. Those with a very optimistic attitude believe that they can get substantial increases in opportunity with only small increases in risk. Those with a pessimistic attitude believe that each small increase in opportunity leads to a substantial increase in risk.

\section{The assessment of threat}

There are many ways of assessing threat. The personal way, though also the most circular, is to ask people what they find the most threatening. The scores given to threatening events can be taken as a measure of the threat perceived by that person. The difficulty with this approach is that although it may be personal it is very difficult to compare threats across different people. Therefore, attempts have been made to average the threat scores given by different people and thus provide a list of average threats, as perceived by people in general. Such lists are still based on subjective perceptions, but represent the views of the wider community.

Rachman (1980) has outlined the characteristics of threatening stimuli which seem to give rise to most adjustment problems, or in his terms, to give rise to the greatest difficulty in emotional processing. Stimuli which are sudden, intense, and dangerous are naturally more troublesome than those that are signalled, mild and safe. Stimuli which are unpredictable, uncontrollable, which happen irregularly and in large chunks are harder to process than those which are predictable, controllable, regular and which happen in small chunks. There is also an additional problem when the stimuli relate to instinctive "prepared" fears. In summary, the very worse stress would appear to be something that happens suddenly, without warning, is intense and dangerous, taps into a prepared and instinctive fear, appears to be uncontrollable and unpredictable, happens on a irregular basis and comes in very large chunks. These are the primary features of most disasters.

The other approach is to get an estimate of hazard without asking about individual perceptions. These estimates may be based on death rates, or possibly time off work because of sickness or injury. This actuarial approach is far more objective, but is easier to apply to major hazards rather than moderate stressors which may cause distress but not threat to life.

Whatever the technique used, there is general agreement that some events are likely to be ranked higher than others, and that the severe and sustained life threat experienced by, for example, the extermination camp survivor would be rated more highly than a frightening event of short duration.

\section{$\underline{\text { Japanese study }}$}

In 1988 I gathered and analyzed data on the risk perceptions of 3121 college students of Geography in 13 nations. As part of questionnaire on health risks and political attitudes the students were asked to rate the likelihood of 16 hazardous events happening to them in their lifetime. These included natural disasters, accidents and illnesses. Through the kind help of 


\section{$\underline{\text { Table } 1}$}

Estimated likelihood ratings, on a 7 point scale, of being killed or injured by a number of hazards, given by 262 Japanese students

\section{Hazard}

Traffic accident

Cancer

Die prematurely

Natural disaster

Nuclear war

Heart disease

Aeroplane crash

Nuclear power accident

Physical handicap

Bronchitis

Mental illness

Criminal violence

AIDS

Food poisoning

Suicide

Alcohol or drugs
Mean score Ranking in world

$4.65 \quad 1$

$4.59 \quad 1$

$4.16 \quad 1$

$4.07 \quad 1$

$3.94 \quad 1$

$3.65 \quad 2$

$2.94 \quad 1$

$3.94 \quad 2$

$3.63 \quad 2$

$3.23 \quad 1$

$3.13 \quad 1$

$3.00 \quad 2$

$2.84 \quad 1$

$2.68 \quad 1$

$2.38 \quad 1$

$2.10 \quad 2$

Professor Akinobu Terasaka I was able to include 262 students from Tokyo Metropolitan University, who were 20 years of age on average. Their responses were significantly different from those obtained from students in Europe, Scandinavia, America and Australia. Japanese students were more likely than other students to see judge that the hazardous events were very probable. Out of the 16 hazards they gave the highest risk ratings of any nation on 11 occasions and were in second place on 5 occasions. (See Table 1). They estimated their probable lifespan as being 69.55 years, which was the shortest estimate, and which is directly against the evidence which places Japan as having one of the highest longevity rates in the world.

As regards health behaviour they were in first place in the world for believing that they could improve their health by seeing their doctor regularly and by avoiding food additives. They were in 9th place for avoiding tobacco and in last place for avoiding alcohol.

They were then asked to state how much they agreed, on a 7 point scale, with a series of statements about risks and safety. These results, which are shown in Table 2, are particularly interesting. They were more likely than any of the other nations to believe that: personal health was due to chance and that there was nothing an individual could do about it; that health warning exaggerated dangers; that most things in life were more important than 


\section{$\underline{\text { Table } 2}$}

Agreement ratings, on a 7 point scale, to statements about "your general attitude to life, particularly about risks and the actions you can take to manage them", given by 262 Japanese students

Mean score Ranking in world

Personal health is determined by chance events and there is nothing an individual can do about it Health warnings exaggerate dangers in order to frighten people into paying attention

2.87

3.19

4.41

4.72

5.20

5.16
1

1

6

11

1

1

1

1

7

6

13

My health at present is good

bothering to take health precautions; that high technology medicine created as many problems as it cured; and that it was better not to worry about things which may never happen, even though they might sometimes suffer because they had not followed a warning. They were the least likely nation to believe that their health was good, and were in 11th place in believing that if they took the right actions they could stay healthy. All of these results suggest a relatively fatalistic attitude to risk and personal health. However, they were also in first place in agreeing with the statement that not enough warnings were given about threats to their lives.

In terms of their general political attitudes Japanese students were strongly realistic, religious, ethnocentric and fairly conservative. They were 12th out of the 13 countries in accepting the pleasures of life, and not restricting themselves in these pleasures. 
To attempt an overall summary, Japanese students are very aware of risks. They have the highest scores among the 13 nations in their ratings of the likelihood of a wide range of hazards. They appear to have a very vigilant approach to risk, and want to have warnings of hazards. At the same time, compared to other nations, they have a relatively fatalistic attitude to health risks, and do not appear to have acted upon warnings. They regard their health as poor, and their lives as likely to be relatively short.

Although this is a relatively small sample of Japanese students, and one must always be wary of questionnaire techniques in cross-cultural studies, the results appear to present something of a dilemma for public policies which are directed at safety control. It may simply be a case that the students had fatalistic private attitudes, but at the same time their public behaviour was a dutiful observation of safety rules. Whatever the explanation, Japanese public policies in preparing for disasters may have to deal with an attitude of mind which could be characterized as "Risk-Aware Fatalism".

\section{$\underline{\text { Disasters and stress responses }}$}

From a research point of view, disasters can be considered as natural experiments, in which un-selected groups of people are subjected to events which are outside the range of ordinary human experience. As such they have implications for the understanding of the causes and development of stress related disorders. They may help us to understand more about the nature of anxiety and depression, and why it is that so many people are able to cope with adversity without major psychological ill affects. However, these objectives can only be achieved if observations are linked to explanations, and these explanations are then tested against new data.

The explanations which tend to be given about stress reactions are often simple and nontheoretical. Arguments are drawn by analogy from the engineering of solid structures, where stress is the force per unit area exerted between contiguous bodies or in parts of a body. This is commonly depicted as a large weight resting on a fragile and unstable structure. As a term, stress is often used situations in which strain would be more appropriate. "Strain" describes the case where objects are stretched tightly and made taut and exercised to their greatest possible extent. Compressive stress is what a large weight applies to anything beneath it. Strain is the extent to which the supporting structure is deformed and compressed by the weight above. By plotting stress against strain it is possible to derive what is called the "elastic modulus" for any material, and this measure allows architects and engineers to choose appropriate materials to bear particular loads. Common to all these views of psychological stress is the notion that when a soft human body comes into contact with hard objects, damage is likely to result. By analogy, events are seen as hard objects which weight a person down, and which require an elastic and stable structure to withstand.

The term "stress" is used so loosely that distinctions are often not drawn between cause and effect. This has led to considerable confusion both in public perceptions and in the stress literature. Properly speaking, stress is not an object in the world. It is the reaction of an organism to events in the world. In order to make this distinction clear it is usual to distinguish between stressors, which are objects and events in the world, and stress reactions, 
which are a variety of physiological and psychological responses when confronted with a stressor. Typically, stressors are defined as things which can cause harm to an organism, though the notion of harm has been cast widely to include psychological concepts such as well-being and self-esteem. In the case of major threats to life, stressors can be determined objectively. In the case of minor stressors, there is an element of circularity, because, for example, a particular cutting remark could only be defined as a stressor by asking the recipient if they had been distressed by it.

\section{Early research on stress}

Early researchers such as Cannon (1932) and Selye (1950) were primarily concerned with the ways in which organisms withstood prolonged and severe environmental stresses. Selye in particular depicted stress as a defence against an adaptation to external environmental challenge. He described a general adaptation syndrome in which the organism first alerted itself to the challenge, secondly summoned its resistance and finally, if the challenge continued, went into a state of exhaustion. Selye's work has been criticised as simplistic, because it has taken a general view of stress reactions, limited itself to physical stressors and underplayed psychological considerations, particularly the role of intervening psychological states.

More recent work has tried to classify stressors in more detail. In particular, distinctions must be drawn between acute and chronic stress and attention must be paid to how much warning is given and what coping responses are available to the organism. Spielberger (1966) has argued that whereas all people respond similarly to physical threats, responses to ego threats are determined by personality. Habitually anxious people show very strong reactions to threats to self-esteem and wellbeing at a psychological level.

Lazarus and Folkman (1984) have proposed that stress should be seen as "a particular relationship between the person and the environment that is appraised by the person as taxing or exceeding his or her resources and endangering his or her well-being" (pg.19). This model moves away from the passive model of physical objects to one in which an active organism has a real or perceived capacity to meet the real or perceived demands of the world. Lazarus has stressed that it is the perception of demand and capacity which determines stress levels. This view underplays the possibility that real demands and real capacity are the determining factors in most cases.

Hobfoll $(1988,1989)$ has argued that this model has serious shortcomings in its present form. First, it does not separately define demand and coping capacity, which are the two sides of the model. Unless this can be done arguments about balance will always be circular. Additionally, measures of demand and coping capacity are often made after the challenging event. A far more powerful test is to determine these in advance and then observe the outcome. The purely perceptual nature of the model as specified by Lazarus means that if a person is successfully coping with a heavy demand this will not be perceived as stressful, and this success at adapting will fall outside of the field of study simply because the successful individual does not perceive himself or herself as being under stress. 
More generally, even if demand and coping capacity can be identified, I would argue that there is a great problem in deciding what meaningful units they should be measured in. In engineering, of course, this is less of a problem. Engines can be rated for their horse power and their efficiency and there are clear formula which allow the engineer to translate that power into useful work. It is precisely this ability to measure in meaningful units which allows an engineer to decide whether a particular engine will be capable of carrying out a particular job. Psychology is not yet able to provide these meaningful units. There is no central paradigm strong enough to allow us to assemble our many observations into coherent calculations about capacity. Until such a time, we have to produce rankings rather than absolute measures of demand and capacity.

\section{The assessment of loss}

Again, as with threat, the measurement of loss, anticipated or actual, can be approached from the personal subjective point of view, and the objective statistical point of view. From a subjective point of view, the loss of even a small memento may have considerable emotional impact. Seen purely from an objective standpoint, such a loss would not be considered life threatening and would be given a low loss value. The personal approach concentrates on the meaning of the particular loss for the individual. Loss of status, loss of memorabilia and loss of love can all be given a personal score by the individual concerned. The statistical approach seems cruder, harsher, but more systematic. It looks at human loss the way an insurance company would do, and tries to apportion amounts according to previously established rules about what various losses are worth. This seems a horrible approach to human suffering, because it is evident that it is appearing to attempt to repair the loss but doing so in the wrong currency. This sort of approach accords a value the loss of a limb, to the loss of an eye, to a loss of a life and makes judgments about all material losses as if they could be determined either by replacement value, that is to say the cost of buying something to replace it, or market value, that is to say the value you would get if you had sold the object in question.

Such a measure of loss would put personal injury, bereavement, the loss of housing and the loss of all material objects on the same scale. In actual practice this scale would be a conceptual model only. Face to face with an individual survivor you would be working with their own perceptions and their own meanings. However, when trying to explain the factors which accounted for the particular reactions of a large number of survivors, it is necessary to consider what can be called the monetary version of loss as a potential explanation for the severity of reactions. It is unlikely to tell the whole story because it leaves out personal meaning, but since these scales have been established over many years by people who have had to deal with a large number of victims, they may have more explanatory power than is generally realised.

\section{$\underline{\text { Response-specificity }}$}

Another useful simplification is the view that threat phenomena cause reactions of anxiety, and loss phenomena cause reactions of depression. Threats imply that the person should remain tense because the world has been shown to be more dangerous than they had 
previously realised. There is evidence that anxious subjects are sensitized in their perception of threat stimuli, and may have a bias in processing information related to personal threat (Mathews and Eysenck, 1987).

Losses cause depression because they deny survivors things to which they had already formed attachments. Since development involves making affectional bonds, people come to accept this as the usual levels of reward they get in their every day life. When these bonds are broken, the level of daily reward goes down, and depression is the result. This view suggests that, within certain ranges, we habituate to the level of reward we experience and come to expect it as the norm.

One consequence of this approach is that it becomes very important whether the survivor views a particular object or person as being replaceable. One would expect that the more unique and intense the relationship the smaller the chance of a replacement being found. It would also suggest that people have some internal understanding of life expectation and will be less affected by the loss of a person who is elderly, and who had fewer years to live. On a simple reward model, it could be calculated that the future reward from the elderly person was limited, and so that the real loss if that person dies is low. There would be the sadness of loss of attachment, but it would be manageable. Again, following this harsh view of personal relations, the cost of an elderly person may be high in the sense of them having high dependency needs, so that on balance, in terms of social relationships, someone who is having to care for an elderly person may eventually be rewarded by their death. If the dead person passes on their goods to the survivors then again the balance of reward will be in favour of the person's death.

The reward model may explain why the death of an elderly relative or parent should not be too difficult to cope with. Following this model, it could also be argued that the greatest loss would be of the person from whom most was expected, and that is one's child. One would expect to have their affection and attention all the days of one's life. Their death would be considered the greatest loss of reward.

Our knowledge of stress is rich in descriptive detail, but weak in objective measurement and conceptual development. The study of disasters, if linked to a more closely specified resources model, and carefully measured assessment of threat and loss, may yet give us the better understanding which will create more accurate measures of human resilience, and better techniques to help those who find that the demands of a trauma exceed their own capacity to cope.

\section{$\underline{\text { Responses to disasters }}$}

There are numerous descriptions of the problems subsequently reported by disaster survivors (Raphael, 1986; Figley, 1985; Quarentelli, 1985; Horowitz, 1976; Drabeck, 1986; Thompson, 1988; Wilson and Raphael, 1993, Green, 1994), and there have been over 1000 publications on post-traumatic responses in the last few years. There are great difficulties in ensuring that different studies use the same criteria and set the same levels when describing psychological distress. However, as a rough rule of thumb, $25 \%$ of those exposed to a life threatening event 
go on to develop post-traumatic stress disorder. The actual rates vary according to the nature of the event, ranging from $12 \%$ of those who have accidents to $80 \%$ of those who are raped. Very rough estimates suggest that helpers and rescuers at disasters show a 5\% disorder rate (Thompson and Solomon, 1991; Thompson and Suzuki, 1991; Thompson, 1993), front line troops a $20 \%$ rate, civilians in a disaster a $35 \%$ rate and those who have experienced torture an $80 \%$ rate. These figures suggest that trauma must be severe and sustained before a majority of the victims will show a psychological disorder. Most studies find a dose-response relationship, such that those most exposed have the highest distress rates. Vulnerability factors include low education and social class, pre-existing psychiatric problems, prior traumatic experiences and, to some extent, female gender. The nature of human responses to extreme stress are far wider than that described by post-traumatic stress disorder. Survivors often also suffer from major depression, phobic disorder, generalized anxiety disorder, substance abuse and sexual dysfunction. It is claimed that clinical samples of trauma survivors are 8 times more likely to commit suicide, but this has not been found for large scale samples of Vietnam combat veterans, whose suicide rates are very similar to men who did not experience combat.

\section{Earthquakes}

There is an extensive literature on human reactions to earthquakes, with at least 69 English language psychological papers in the last five years, and these cannot all be reviewed here. Most of these studies confirm extensive psychological impact for those in the epicentre of destruction, but the wide variety of assessment techniques and threshold levels, together with the infrequent use of control groups makes it difficult to be precise about the real social consequences of these psychological reactions. A few studies have been picked out as illustrations of particular findings.

Odaira, Iwadate and Raphael (1993) studied early human reactions to Japanese earthquakes, reporting on the Miyagi-oki earthquake of June 1978 and the Tokachi-oki of May 1968, and finding that $28 \%$ of people said that they had not behaved calmly, with women showing more alarm than men, and an average of 3.7 psychological complaints per person overall. McFarlane and Hua (1993) reported on the Yunnan earthquake in China on November 1988. In the most severely affected regions there was an approximate doubling of the psychiatric morbidity rates six months after the disaster, with $60 \%$ of the population being above the cutoff point on the General Health Questionnaire. By this time most people had been rehoused and public services had been re-instituted. The reactions were mostly expressed as bodily symptoms, not mental ones. There was a weak dose response relationship, with only a $17 \%$ greater morbidity in the most affected areas.

Andersen and Manuel (1994) investigated gender differences in stress response to the Loma Prieta earthquake. 108 men and 103 women completed 2 standardized stress measures (the Impact of Event Scale and the SCL-90--Revised) and answered open-ended questions regarding their experience of the earthquake. Results show that women reported experiencing greater amounts of stress in response to the earthquake. Women also estimated that the earthquake lasted significantly longer than did men.

Freedy et al.(1994) studied the Sierra Madre, US, earthquake of June 1991 and found that 
frightening thoughts, irritability, depressed affect, sleep difficulty, hopelessness, tachycardia, temper outbursts, worrying, and feeling critical of others were associated with resource losses due to the earthquake, supporting Hobfoll's conservation of resources model.

Pennebaker and Harber (1993) examined 789 San Francisco residents after the Loma Prieta, US, earthquake and from 2,188 Dallas residents during and after the Persian Gulf War, and found evidence to support a social stage model of coping. Immediately after an upheaval, individuals openly talk and think about the event for approximately 2 weeks. Following this emergency stage, individuals progress into an inhibition stage wherein they stop talking about the upheaval but continue thinking about it for approximately 6 weeks. Certain indicators of distress, such as hostility and dreaming, peak during the inhibition phase. After this time, people enter an adaptation phase wherein they neither talk nor think about the upheaval. Reshetnikov et al (1989) presented another phase model of reactions when they examined the behaviour, psychophysiological reactions, state, and effective performance of 70 19-35 year old male earthquake victims 4 days after an earthquake. Four consecutive phases were identified: acute emotional shock (lasted 3-5 hours), psychophysiological immobilization (up to 3 days' duration), the resolution stage (from the 3rd to the 12th day after the earthquake), and the recovery stage (from the 12th day onward).

Goenjian (1993) reported on an international mental health relief program for children and adults which was implemented in Soviet Armenia after the December 1988, Spitak earthquake. He discussed the selection, preparation, and support of mental health workers for the relief work; methods that facilitated the screening and treating of students in classrooms; and found a rate of post-traumatic stress disorder of $74 \%$ and of major depressive disorder of $22 \%$ in 582 victims who entered treatment 3-6 months after the earthquake.

Mileti and O'Brien (1992) tested the theory of risk communication with data on public perception of risk and response to aftershock warnings during the post-impact Loma Prieta, US, earthquake emergency. Findings from 918 households in Santa Cruz and 734 households in San Francisco counties were consistent, and confirmed established propositions. They concluded that the social psychological process that explains post-impact public warning response is not identical to the one that explains public response to pre-impact warnings. The lack of mainshock damage created a normalization bias for nonvictims. This bias constrained perception of risk to damaging aftershocks and protective response to warnings.

Nolen Hoeksema and Morrow (1991) had by chance taken measures of emotional health and styles of responding to negative moods on 137 students 14 days before the Loma Prieta, US, earthquake. A follow-up was done 10 days and again 7 weeks after the earthquake to test predictions about which of the students would show the most enduring symptoms of depression and post-traumatic stress. Regression analyses showed that students who, before the earthquake, already had elevated levels of depression and stress symptoms and a ruminative style of responding to their symptoms had more depression and stress symptoms for both follow-ups. Students who were exposed to more dangerous or difficult circumstances because of the earthquake also had elevated symptom levels 10 days after the earthquake. Similarly, students who, during the 10 days after the earthquake, had more ruminations about the earthquake were still more likely to have high levels of depressive and stress symptoms 
7 weeks after the earthquake.

\section{Bombings, hijackings and accidents}

By way of illustration of some of the investigations being carried out, I am currently working on data on psychological distress, sickness absence, hours of therapy and therapeutic outcome, age, occupation, seniority, and exact location at the time of the bombing which were collected from 115 individuals who were working in a large store adjacent to the bomb explosions in Warrington, United Kingdom, on 20th March 1993. Two children died in this bombing, and about 50 adults and children were injured, with several requiring amputations. The above measures were collected three weeks after the bombing and repeated seventeen weeks later. There was a follow-up 16 months after the bombing. Analysis demonstrated relationships between the degree of exposure to the blast, age and seniority with levels of psychiatric morbidity, severity of emotional reactions, hours of therapy, and subsequent emotional adjustment. For those who were most exposed to the bombing, by virtue of being on the ground floor when it happened, the time lost for sickness absence doubled. There was a direct dose-response relationship, showing clear effects of exposure to the bomb, particularly when subjects were considered floor by floor. Location in the store was more important than distance from the explosion, most probably because injured people made their way to the dispensing area at the back of the store, so that staff there had even greater exposure to the distress and suffering of the public. Most staff members coped fairly well with the psychological effects of the incident, at least as shown by the standardized screening questionnaires utilized. Most staff members got better, in the sense that their distress scores went down with time, and as a consequence of treatment. Those staff members who eventually resigned from the store in the following year were not significantly more distressed than those who stayed, though there are some suggestive indications which need further analysis.

The effects of sustained threat are illustrated by a study carried out on the psychological reactions of subjects who survived the hijacking of a Kuwait Airways jet in April 1988 (Thompson, 1991). Airplane hijackings are a well publicised method of taking hostages, and hijackings of aircraft have taken place since the 1930s. Airplane hijackings with their attendant publicity are still frequent occurrences with about seven major hijacks occurring each year. Aircrafts are a prime target because they seem to offer a means of escape as well as providing ready-made hostages. Most aircraft are also very difficult to storm and therefore afford some protection to the hostage takers. Hostage reactions generally follow a first stage of alarm, followed by resistance and then, as time passes, by exhaustion. The hostages may become emotionally involved with their captors and this development of empathy may increase the hostages chance of survival. Hostages may have a strong feelings of resentment against authorities such as airline and government officials. Post-trauma anxiety, health problems and even clinical depression are reported to afflict survivors after their release. Other delayed effects include anxiety responses such as nightmares, startle reactions to loud noises and inability to concentrate. Subjects were sent questionnaires within two weeks of their release, and 13 of the 22 survivors replied. Eight of these subjects were showing probable psychological distress, and in three of them this was in the severe category. The most common complaints were of anxiety and intrusive memories, and to a lesser extent an 
inability to function properly at home and at work. Nine survivors replied to a follow-up six months later, and four of them were still above the cutoff point for psychological distress.

On the eighteenth of November 1987, at the end of the evening commuter rush hour, there was a major fire at King's Cross Underground Railway station in London, United Kingdom (Turner, Thompson and Rosser, 1993). Thirty one people died, several hundred were present and many more were affected by the experience. In fires, there is a tendency for people to use familiar routes and exits and to assume familiar roles. In evacuating buildings on fire, people choose the way out they know best, run away from smoke, tend to follow a leader, head towards brighter places such as windows and some will shut themselves in a room after successfully evacuating (Canter, 1990). At Kings Cross, there were the additional disorientating factors of being underground and of being inside a structure which was highly complex and only small parts of which were known to most people. Evacuation plans were sketchy and conflicting. There was a low level of emergency training. It was a matter of subsequent regret and guilt for some of the officials that passengers had been mistakenly directed into the heart of the disaster.

The group of 50 people which was studied in detail comprised 22 passengers bereaved and injured, 18 emergency services personnel (police, ambulance, fire services), 8 underground transport staff and 2 whose role was not known. There were 34 men and 16 women and the mean age of the whole group was 36 years.

The group contained many people with evidence of psychological distress. Mean scores on the General Health Questionnaire-28 were 10.0 (sd 7.7). Scores above 4 are often considered to be indicative of probable caseness. In this sample, $66 \%$ had scores above this value. The total Impact of Event Scale score was 31.0 (sd 18.4), which is similar to stress clinic norms.

The 20 subjects who had contacted their family doctors following the fire had significantly higher distress scores (eg for the GHQ, mean scores were 13.1 versus 7.2, $t=2.8 ; p<0.001$; $\mathrm{n}=47$ ). This may be taken as relatively crude evidence supporting the validity of the scales. Those who had decided that they needed to obtain medical assistance also scored highly on subjective distress on the screening instrument.

Of the 43 people who were able to talk about the disaster soon afterwards, $81 \%$ reported that they found it helpful. Of the 24 subjects who were able to talk in considerable detail, $92 \%$ reported subjective benefit. Thus early debriefing may be a valuable component of the disaster response, although at this stage objective evidence is lacking.

The profound effects of a sudden life threat are illustrated by sinking of the Marchioness river boat in London, United Kingdom, on 20th August 1989, in which fifty-one people died and 80 survived, a death rate of $39 \%$. (Thompson et al. 1994). On measures of intrusive memories and of psychological difficulties the 27 subjects studied were significantly higher than population norms, and somewhat higher than psychiatric in-patient populations. Personality measures taken after the disaster showed that neuroticism scores were very much higher than population norms, but personality measures were not correlated with distress. The traumatic event was so sudden that there was no real way to establish different exposure measures. 
Table 3: Most and least frequently reported items on the Ways of Coping Checklist

\begin{tabular}{|c|c|}
\hline 10 most frequently reported coping items & $\begin{array}{l}\% \text { of sample } \\
\text { using "at least } \\
\text { somewhat" }\end{array}$ \\
\hline 1. I tried to keep my feelings to myself & $87 \%$ \\
\hline 2. Wished that I could change what had happened or how I felt & $86 \%$ \\
\hline $\begin{array}{l}\text { 3. Wished that the situation would go away or somehow be } \\
\text { over with }\end{array}$ & $85 \%$ \\
\hline $\begin{array}{l}\text { 4. Turned to work or substitute activity to keep my mind off } \\
\text { things }\end{array}$ & $81 \%$ \\
\hline $\begin{array}{l}\text { 5. I tried to keep my feelings from interfering with other things } \\
\text { too much }\end{array}$ & $80 \%$ \\
\hline 6. Just concentrated on what I had to do next - the next step & $79 \%$ \\
\hline $\begin{array}{l}\text { 7. I felt that time would make a difference - the only thing to } \\
\text { do was to wait }\end{array}$ & $76 \%$ \\
\hline 8. Accepted sympathy and understanding from someone & $73 \%$ \\
\hline 9. Kept others from knowing how bad things were & $73 \%$ \\
\hline 10. Talked to someone about how I was feeling & $72 \%$ \\
\hline 10 Least frequently reported items & $\%$ of sample \\
\hline 1. Found new faith & $23 \%$ \\
\hline 2. Tried to get the person responsible to change his or her mind & $25 \%$ \\
\hline $\begin{array}{l}\text { 3. I thought about how a person I admire would handle this } \\
\text { situation and used that as a model }\end{array}$ & $26 \%$ \\
\hline 4. Took a big chance or did something very risky & $28 \%$ \\
\hline 5. Realized I brought the problem on myself & $29 \%$ \\
\hline 6. I came out of the experience better than I came in & $30 \%$ \\
\hline $\begin{array}{l}\text { 7. Drew on my past experiences; I was in a similar situation } \\
\text { before }\end{array}$ & $35 \%$ \\
\hline 8. I jogged or exercised & $37 \%$ \\
\hline 9. Came up with a couple of different solutions to the problem & $38 \%$ \\
\hline 10. a) Changed something so things would turn out alright. & $39 \%$ \\
\hline b) Apologized or did something to make up. & $39 \%$ \\
\hline c) Went on as if nothing happened & $39 \%$ \\
\hline
\end{tabular}

\section{Coping Stategies}

108 survivors of trauma attending a stress clinic were assessed on measures of coping, personality, control expectancies and psychological distress. Although cross-sectional studies can only be indicative, it would appear that most coping strategies, and particularly Escape Avoidance, are consistently associated with high psychological distress, with the exception of Positive Reappraisal and Distancing, which are the only strategies associated with better psychological health. It may be that deeply distressed survivors cannot find effective ways of obtaining relief, and therefore report many ways of trying to cope. The most and least 
common ways are shown in Table 3.

A second regression analysis was carried out using those subjects $(n=64)$ who later received psychological therapy for post traumatic stress reactions and were reassessed 2 months later. Distancing was still negatively associated with distress and accounted for approximately $4 \%$ of the variance in distress scores after partialling out the other variables and pre-therapy scores.

\section{Treating trauma: Psychotherapy, debriefing and CEASE}

I can report on three treatment trials conducted at our clinic. Subjects were drawn from a variety of life-threatening disasters, and had high scores on the Impact of Events scale and the General Health Questionnaire. In the first trial subjects were allocated to either immediate treatment $(n=29)$ or to treatment after an eight week waiting period $(n=13)$. Treatment consisted of eight weeks of psychotherapy in which the precipitating trauma was the focus of discussion. Measures were taken at the beginning of the waiting period, at commencement of treatment, at the end of eight treatment sessions, and also at the final completion of treatment for a minority who had required further sessions.

In the second trial, after they had received a full interview and questionnaire assessment, subjects were given an immediate debriefing of about three hours duration. They were then randomly allocated to eight weeks of psychotherapy as before $(n=18)$, or to eight weeks in which their progress was monitored by very brief postal questionnaire $(n=24)$.

The third treatment trial was an open trial $(n=23)$ of cognitive behaviour therapy, which has been given the acronym CEASE (Conditioned - Engram - Anxiety - Stimulus - Extinction) (Hacker-Hughes and Thompson, 1994). The patient inclusion and assessment techniques were the same as those used in the first two trials. In this treatment condition patients received four sessions of imaginal desensitization and four sessions of in vivo desensitization to their trauma. Sessions were tape recorded and patients were encouraged to listen to the tapes between treatments. The results are shown in tables 4 and 5. Debriefing on its own appeared to be as effective as debriefing plus psychotherapy and as psychotherapy on its own, and was more cost effective. CEASE showed the greatest treatment effects, and is currently given as the treatment of choice.

\section{Implications for safety control and risk management}

Faced with the ever present threat of earthquake, and the more episodic threats of terrorism, Japan must seek a way of managing the collective risks the nation faces. Insufficient or incorrect preparation will leave the nation open to the damaging consequences of major risks. On the other hand, too great an investment in attempting to prevent unavoidable hazards would be a useless waste of resources. A search for order is understandable, but natural catastrophes bring inevitable chaos. A major earthquake is, in terms of human life spans, a relatively rare event. Its consequences are considerable destruction. These are the sorts of hazards that individuals tend to discount. They cannot maintain high levels of vigilance for such long periods. The costs in terms of anxiety and interruption of normal activities are too high. 


\begin{tabular}{|c|c|c|c|c|c|c|c|c|}
\hline \multirow[t]{2}{*}{ Condition } & \multirow[t]{2}{*}{$\overline{\mathrm{N}}$} & \multirow[t]{2}{*}{ Measure } & \multicolumn{2}{|c|}{ Begin 8 weeks } & \multicolumn{2}{|c|}{ End 8 Weeks } & \multicolumn{2}{|c|}{ Reduction } \\
\hline & & & Mear & $(\mathrm{SD})$ & Mean & (SD) & $\%$ & sd \\
\hline Waiting List & $\overline{13}$ & $\mathrm{TES}$ & 43.16 & (19.9) & 34.46 & (17.9) & $20 \%$ & .46 \\
\hline Psychotherapy & 29 & TES & 42.27 & $(13.8)$ & 31.55 & (19.3) & $25 \%$ & .64 \\
\hline Debriefing & 20 & TES & 42.84 & $(16.2)$ & 34.35 & $(17.7)$ & $20 \%$ & .50 \\
\hline Debriefing \& Therapy & 13 & TES & 44.07 & $(14.7)$ & 36.07 & $(17.9)$ & $18 \%$ & .49 \\
\hline CEASE & 23 & TES & 47.87 & $(16.0)$ & 27.70 & $(18.9)$ & $42 \%$ & 1.16 \\
\hline
\end{tabular}

Table 4

\begin{tabular}{|c|c|c|c|c|c|c|c|c|}
\hline \multirow[t]{2}{*}{ Condition } & \multirow[t]{2}{*}{$\bar{N}$} & \multirow[t]{2}{*}{ Measure } & \multicolumn{2}{|c|}{ Begin 8 weeks } & \multicolumn{2}{|c|}{ End 8 Weeks } & \multicolumn{2}{|c|}{ Reduction } \\
\hline & & & Mear & (SD) & Mean & (SD) & $\%$ & sd \\
\hline Waiting List & 13 & $\overline{\mathrm{GHQ}}$ & 49.38 & $(18.1)$ & 40.61 & (18.9) & $78 \%$ & .47 \\
\hline Psychotherapy & 29 & $\mathrm{GHQ}$ & 44.37 & $(12.5)$ & 29.24 & $(12.3)$ & $34 \%$ & 1.22 \\
\hline Debriefing & 20 & $\mathrm{GHQ}$ & 38.10 & $(17.7)$ & 25.75 & (13.5) & $32 \%$ & .77 \\
\hline Debriefing \& Therapy & 13 & $\mathrm{GHQ}$ & 35.82 & $(13.4)$ & 30.07 & $(14.4)$ & $16 \%$ & .42 \\
\hline CEASE & 23 & GHQ & 47.57 & $(19.1)$ & 26.96 & $(18.2)$ & 439 & 1.11 \\
\hline
\end{tabular}

Table 5

Perhaps the "Risk-Aware Fatalistic" approach to such major catastrophes is psychologically sound. It views all of life as very risky, it seeks warnings wherever possible, but at the same time the psychological impact of these warnings about risks seem to be discounted, possibly in a fatalistic way, so that they do not interfere with the enjoyment of life's pleasures.

\section{References}

Anderson,K.M.; Manuel,G. Gender differences in reported stress response to the Loma Prieta earthquake. Sex-Roles; 1994 May Vol 30(9-10) 725-733

Cannon, W.B. The wisdom of the body (2nd ed.). New York, Norton, 1932.

Canter, D. (1990) Fires and Human Behaviour (2nd Edition). London: David Fulton.

Dowie, J and Lefrere, P. (Eds) Risk and Chance. Open University: Milton Keynes, 1980.

Drabeck TE. Human Responses to Disaster: an Inventory of Sociological Findings. Springer-Verlag: New York, 1986.

Figley CR (ed) The Study and Treatment of Post-Traumatic Stress Disorder. in Trauma and its Wake, volume 1. Brunner/Mazel: New York, 1985. 
Freedy,J.R.; Saladin,M.E.; Kilpatrick,D.G.; Resnick,H.S. Understanding acute psychological distress following natural disaster. Journal-of-Traumatic-Stress; 1994 Apr Vol 7(2) 257-273

Goenjian,A. A mental health relief programme in Armenia after the 1988 earthquake: Implementation and clinical observations. British Journal of Psychiatry; 1993 Aug Vol 163 230-239

Green, B.L. (1994) Psychosocial Research in Traumatic Stress: An Update. Journal of Traumatic Stress, 3, 341-362.

Hacker Hughes, JGH and Thompson, J. (1994) Post-traumatic stress disorder: An evaluation of behavioural and cognitive behavioural interventions and treatment. Clinical Psychology and Psychotherapy, 1, 125-142.

Hobfoll, S. Conservation of resources: A new attempt at conceptualizing stress. American Psychologist, 1989, 44, 3, 513-524.

Hobfoll, S. The ecology of stress. Washington DC, Hemisphere, 1988.

Horowitz, M. Stress response syndromes. Jason Aronson, New York, 1976.

Lazarus RS \& Folkman S. Stress, Appraisal and Coping. Springer: New York, 1984.

McFarlane, A.C. and Hua, C. (1993) Study of a major disaster in the People's Republic of China: The Yunnan Earthquake. In Wilson, J.P. and Raphael, B. (Eds) International Handbook of Traumatic Stress Syndromes. Plenum Press: New York, 1993.

Mathews, A. and Eysenck, M.W. Clinical anxiety and cognition. In H.J.Eysenck and I.Martin (Eds.) Theoretical foundations of behaviour therapy. New York, Plenum, 1987.

Mileti,D.S.; O'Brien,P.W. Warnings during disaster: Normalizing communicated risk. Social Problems; 1992 Feb Vol 39(1) 40-57

Nolen Hoeksema,S. and Morrow,J. A prospective study of depression and posttraumatic stress symptoms after a natural disaster: The 1989 Loma Prieta earthquake. Journal of Personality and Social Psychology; 1991 Jul Vol 61(1) 115-121

Odaira, T., Iwadate, T. and Raphael, B. (1993) Earthquakes and traumatic stress: Early human reactions in Japanese society. In Wilson, J.P. and Raphael, B. (Eds) International Handbook of Traumatic Stress Syndromes. Plenum Press: New York, 1993.

Pennebaker,J.W.; Harber,K.D. A social stage model of collective coping: The Loma Prieta earthquake and the Persian Gulf War. Journal of Social Issues; 1993 Win Vol 49(4) 125-145.

Quarentelli, E.L. An assessment of conflicting views on mental health: the consequences of traumatic events. In: Figley, C.R. (ed) Trauma and its Wake, Volume 1. Brunner/Mazel: New York, 1985. 
Rachman S. Emotional processing. Behaviour Research and Therapy. 1980; 18, 51-60.

Raphael B. When Disaster Strikes. Basic Books: New York, 1986.

Rasmussen, J., Duncan, K. and Leplat, J. (Eds) New Technology and Human Error. John Wiley: Chichester, 1987.

Reason, J. Human Error. Cambridge University Press, Cambridge, 1989.

Reshetnikov,M.M.; Baranov,Y.A.; Mukhin,A.P.; Chermyanin,S.V. Psychological aspects of state, behaviour, and activity of victims in the center of natural calamity. Soviet Journal of Psychology; 1989 Vol 10(4) 115-119.

Selye, H. The physiology and pathology of exposure to stress. Montreal, Acta, 1950.

Spielberger, C.D. Anxiety and behaviour. New York, Academic Press, 1966.

Thompson, J. Psychological Aspects of Nuclear War. Nishimura, Tokyo, 1988. (Japanese). 210 pp.

Thompson, J. Kuwait Airways Hijack: Psychological consequences for survivors. Stress Medicine, (1991), 7, 3-9.

Thompson, J. Theoretical issues in responses to disaster. Journal of the Royal Society of Medicine, (1991), 84, 19-22.

Thompson, J. and M.Solomon. Body recovery teams at disasters: Trauma or Challenge? Anxiety Research, (1991), 4, 235-244.

Thompson, J. and I.Suzuki. Stress in ambulance workers. Disaster Management, (1991), 3, 193-197.

Thompson, J. (1993) Psychological impact of body recovery duties. Journal of the Royal Society of Medicine, 86, 628-629.

Thompson, J., Chung, M.C. and Rosser, R.M. (1994) The Marchioness disaster: Preliminary report on psychological effects. British Journal of Clinical Psychology, 33, 75-77.

Turner,S.W., Thompson, J.A. and Rosser,R.M. The King's Cross Fire: Early Psychological Reactions and Implications for Organizing a Phase Two Response. In Wilson,J.P and Raphael,B. (Eds.) The International Handbook of Traumatic Stress Syndromes. Plenum Press, 1993.

Wilson, J.P. and Raphael, B. (Eds) International Handbook of Traumatic Stress Syndromes. Plenum Press: New York, 1993. 